\title{
Conversa Entre Mulheres: Diálogos Sobre Violência Contra a Mulher
}

\author{
Juliane Braga da Silva, ${ }^{1}$ Márcia Maria Santos da Silva, ${ }^{1}$ Stela Lopes Soares, ${ }^{2}$ \\ Thalanikelson de Oliveira Brito, ${ }^{1}$ Maria Auxiliadora Resende Sampaio, ${ }^{1}$ \\ Heraldo Simões Ferreira, ${ }^{3}$ Heliandra Linhares Aragão ${ }^{1}$
}

\begin{abstract}
RESUMO
Sabe-se que, mundialmente, a mulher é vítima constante de diversas formas de violência, principalmente as que são praticadas por seus maridos e companheiros. A violência contra a mulher tem sido cada vez mais vista como um relevante problema de saúde pública, havendo urgência em instituir programas para detecção precoce e para intervenções efetivas. Nesse contexto, evidencia-se a necessidade de identificação de redes de apoio e atenção voltadas a mulheres em situação de violências. O presente trabalho traz como cenário o grupo de mulheres denominado "Conversa Entre Mulheres", do Centro de Saúde da Família (CSF) território do Padre Palhano, no município de Sobral/CE. Tem-se como objetivo geral promover cuidado e empoderamento de mulheres que vivenciam situações de violência em uma área adscrita do CSF Padre Palhano. Os envolvidos no estudo foram as participantes do grupo de mulheres. Trata-se de uma pesquisa-intervenção que foi realizada nos meses de novembro/2019 a janeiro de 2020. A intervenção foi realizada de forma grupal, em que ocorreram momentos de educação em saúde voltados para usuárias que vivenciam ou presenciam situação de violência contra a mulher. Como resultado, obtivemos o fortalecimento do grupo Conversa Entre Mulheres, gerando pensamento crítico das participantes no reconhecimento e resolução dos seus problemas, tornando-as multiplicadoras do saber e levando informações para outras mulheres que vivenciam situações de violência. A violência contra a mulher tem sido cada vez mais vista como um relevante problema de saúde pública, havendo urgência em instituir programas para detecção precoce e para intervenções efetivas. Diante disso, torna-se cada vez mais necessário preencher os espaços de discussões no intuito de fortalecer a luta das mulheres por garantias de direitos e disseminar informações.
\end{abstract}

Palavras-chave: Violência contra a mulher. Atenção primária à saúde. Políticas públicas. Empoderamento.

\section{CONVERSATION BETWEEN WOMEN: DIALOGUES ON VIOLENCE AGAINST WOMEN}

\section{ABSTRACT}

It is known that, worldwide, women are a constant victim of various forms of violence, especially those that refer to their husbands and partners. Violence against women has been increasingly seen as a relevant public health problem, with urgency in establishing programs for early detection and for effective interventions. In this context, it is evident the need to identify support and care networks aimed at women in situations of violence. The present work presents as a scenario the Group of Women, called "conversation between women", of the Family Health Center territory of Padre Palhano, in the municipality of Sobral/CE. The general objective is to promote care and empowerment of women who experience situations of violence in an area enrolled in the CSF Padre Palhano. Those involved in the study were the participants of the Women's Group. This is an intervention research that was carried out from November/2019 to January 2020. The intervention was carried out in a group way, in which moments of health education were performed for users who experience or witness violence against women. As a result, we obtained the strengthening of the Conversation between Women Group, generating critical thinking of the participants in the recognition and resolution of their problems, making them multipliers of knowledge and bringing information to other women who experience situations of violence. Violence against women has been increasingly seen as a relevant public health problem, with urgency in establishing programs for early detection and for effective interventions. In view of this, it is increasingly necessary to fill the spaces of discussions in order to strengthen the struggle of women for guarantees of rights and disseminate information.

Keywords: Violence against womem. Primary health care. Public policy. Empowermen. 


\section{INTRODUÇÃO}

A violência se constitui na violação dos direitos humanos e das liberdades fundamentais, afetando o direito à vida, à saúde e à integridade física. Trata-se de um fenômeno que atinge mulheres de diferentes contextos, idades, raças, etnias, religião, escolaridade, gerações e classes sociais (GUIMARÃES; PEDROZA, 2015).

Em âmbito mundial, a violência contra a mulher foi uma expressão do movimento social feminista há mais de 20 anos. Tal expressão refere-se a situações tão graves como a violência física, sexual e psicológica cometida por parceiros íntimos, o estupro, o abuso sexual, o assédio sexual no local de trabalho, a violência contra a homossexualidade, o tráfico de mulheres, o turismo sexual, a violência étnica e racial, a violência cometida pelo Estado, por ação ou omissão, a mutilação genital feminina, a violência e os assassinatos ligados ao dote, o estupro em massa nas guerras e conflitos armados (ENGEL, 2015).

Historicamente, a mulher é uma vítima constante de diversas formas de violência, principalmente as praticadas por seus maridos e companheiros. Essas agressões têm muitas vezes como consequência a morte de mulheres que, em alguns casos, por várias vezes, pediram ajuda. Faz-se necessário, no entanto, observar o contexto em que esta está inserida, bem como atentar-se a sinais que indicam que a mulher se encontra em situação de violência (MORAIS; RODRIGUES, 2016).

Nesse contexto, evidencia-se a necessidade de identificação das redes de apoio e atenção voltadas a mulheres em risco de violência. Estas redes constituem-se na articulação entre instituições governamentais, não governamentais e comunidade, e visam a ampliar e melhorar a qualidade do atendimento, o encaminhamento necessário e o desenvolvimento e articulação de estratégias efetivas para prevenção (LETTIERE; NAKANO, 2015).

Em Sobral/CE, no que se refere às redes de apoio, atenção e cuidados a mulheres em situação de violência, verifica-se a existência dos seguintes serviços: Centro de Saúde da Família (CSF) (porta de entrada de saúde da comunidade, na atenção primária); Santa Casa de Misericórdia de Sobral, Hospital Regional Norte e demais unidades de saúde; Centro de Referência da Mulher; Centros de Referência da Assistência Social (Cras) e Centro de Referência Especializado de Assistência Social (Creas); Instituto Médico Legal (IML); Polícia Civil e Militar; Defensoria; Vara da Família; Central de Atendimento à Mulher - Ligue 180 (válido para todo território nacional). Ressalte-se que todos os serviços estão disponibilizados no município, atuando no apoio e atenção, trabalhando de forma intersetorial no cuidado a mulheres vítimas de violência (SOBRAL, 2017).

O Ministério da Saúde (MS), em seu Caderno de Atenção Primária no 8 (BRASIL, 2001), relata que os profissionais de saúde devem estar atentos à saúde da mulher, principalmente aquelas em situação de violência, pois estas são usuárias assíduas dos serviços de saúde, ambulatoriais e hospitalares, constituindo uma clientela expressiva.

Em vivência num CSF no município de Sobral/ $C E$, da residência multiprofissional em saúde da família, apoiando um grupo operativo na execução de um projeto denominado Prevenção em Família (realizado entre agosto/2018 e outubro/2019), composto por dez oficinas com diversas temáticas, cujo objetivo era trabalhar e fortalecer os vínculos entre pais e filhos, foi observado que as participantes traziam constantemente em suas falas questões envolvendo diversos tipos de violência, conflitos familiares e outras expressões da questão social. Nesse sentido, foi debatido com as participantes do grupo, mulheres, maiores de 18 anos, sobre a possibilidade de dar continuidade ao grupo de convivência, ressignificando-o, tratando de vários assuntos relacionados aos interesses das mulheres. Assim, o grupo foi denominado pelas próprias participantes como "Conversa Entre Mulheres" e foi possível identificar a necessidade de uma abordagem mais direcionada à temática violência contra a amulher.

A partir deste contexto identificamos algumas fragilidades do território: conflitos de gangues, o que dificulta o traslado de uma área territorial para a outra (entre bairros rivais); falta de conhecimento de alguns profissionais sobre estratégias de cuidado a mulheres em situação de violência; território com índices altos de violência no âmbito geral, entre outras.

Como potencialidades, temos: respeito e reconhecimento da comunidade pelos profissionais de saúde; boa adesão quando realizamos atividades dentro do CSF; apoio e mobilização dos profissionais quando necessitamos realizar atividades fora do território (geralmente atuamos no centro, bairro não afetado pelas limitações territoriais); abertura dos profissionais para novos conhecimentos a respeito das temáticas; dispomos de espaço físico da unidade, adequado e que atende às nossas necessidades iniciais, suporte e apoio da coordenadora da unidade de saúde. 
Dessa forma foi proposta a seguinte intervenção: desenvolver estratégias para promover o empoderamento e cuidado para mulheres que vivenciam ou presenciam situações de violência da área adscrita do CSF Herbert de Sousa, conhecido como CSF Padre Palhano, localizado no bairro Padre Palhano, município de Sobral/CE (SOBRAL, 2017).

A proposta consistiu na atuação sobre essa problemática da violência contra as mulheres, no grupo "Conversa Entre Mulheres", desenvolvido no referido CSF, haja vista as situações singulares vivenciadas pelas participantes do grupo, que sofrem, já sofreram ou presenciaram situações de violência, seja no âmbito familiar, comunitário e/ou em outros espaços. A proposta objetivou fortalecer o recente grupo criado que se desenvolve como estratégia de cuidado, vínculo e enfrentamento às situações de violência no território, tendo como objetivo deste estudo: promover o cuidado e empoderamento de mulheres que vivenciam situações de violência em uma área adscrita do CSF Padre Palhano.

Assim, foram propostas ações que beneficiem as usuárias do Sistema Único de Saúde (SUS), participantes do grupo de mulheres do CSF Padre Palhano, maiores de 18 anos, moradoras do bairro Padre Palhano, no município de Sobral/CE. Também pretendeu-se contribuir com profissionais que se dispuseram a estar presentes nos momentos da intervenção, sejam da equipe mínima, do Núcleo Ampliado de Saúde da Família (Nasf-AB) e/ou Residentes Multiprofissionais em Saúde da Família.

Diante do exposto, a realização do projeto de intervenção fez-se necessário como estratégia de enfrentamento à violência contra as mulheres, de cuidado no território às situações de violência contra a mulher, de promoção do empoderamento feminino, bem como possibilidade de educação permanente para os profissionais que se fizerem presentes nos momentos da intervenção. A opção por esta pesquisa - intervenção justificou-se, portanto, pela possibilidade de fomentar o senso crítico às usuárias, no que respeita à temática violência, às estratégias de cuidado e o conhecimento das redes de atenção e serviços voltados para o acompanhamento de mulheres em situação de violência.

Pretendeu-se, portanto, contribuir na perspectiva do cuidado prestado a estas mulheres, fortalecimento da rede de proteção a mulheres em situação de violência, contribuindo para o Projeto Terapêutico Singular (PTS) das usuárias. As usuárias foram beneficiadas na medida em que tiveram acesso a espaços de cuidado e identificação dos vários tipos de violência, além das instituições de caráter protetivo, tais como: Centro de Referência Especializado de Assistência da Mulher (Creas), Centro de Referência da Mulher, Delegacia Regional da Mulher, entre outros, e fluxos de cuidado. Os profissionais que apoiaram os momentos se beneficiaram na oportunidade de troca de saberes, conhecimentos das estratégias de cuidado dos referidos equipamentos de proteção e ainda conhecimentos históricos e legais que visam à garantia dos direitos sociais e de saúde das mulheres, bem como a importância e o preenchimento correto da Ficha de Notificação Individual(FNI), de registro de violência interpessoal/autoprovocada, do Sistema de Informação de Agravos de Notificação (Sinan).

\section{MATERIAIS E MÉTODOS}

O presente estudo deu-se por meio de pesquisa-intervenção, em que foi realizada uma abordagem qualitativa sobre o grupo de mulheres, da atenção primária, em um Centro de Saúde da Família (CSF). A escolha da pesquisa-intervenção justificou-se pela possibilidade de fomentar o empoderamento das usuárias, no que respeita à temática violência, às estratégias de cuidado e às redes de atenção.

A pesquisa-intervenção, segundo Romagnoli (2014), é um estudo que é realizado em conjunto com a população, tendo em vista a modificação processual do objeto da pesquisa, que se dá por meio de intervenções diante da rotina dos estabelecimentos. 0 mesmo autor ressalta que a pesquisa se apresenta indissociada de uma intervenção compromissada a dar apoio efetivo na construção de uma sociedade mais digna, fraudando os moldes iluministas que seguem a neutralidade, a objetividade e a verdade fundada em uma postura apolítica e racional.

A abordagem da pesquisa é qualitativa, pois seu foco está na natureza subjetiva do objeto analisado. Conforme Bazanini, Ribeiro e Bazanini (2014), esta abordagem como exercício de pesquisa não se apresenta como uma proposta rigidamente estruturada, permitindo que a imaginação e a criatividade levem os investigadores a propor trabalhos que explorem novos direcionamentos.

A intervenção foi desenvolvida no CSF Herbert de Sousa, localizado no bairro Padre Palhano, no município de Sobral/CE, que já consiste num espaço de cuidado e promoção em saúde no território. Segundo dados da territorialização, o bairro, no mês de agosto de 2019 , conta com uma população de 10.263 pessoas, das quais 4.942 do sexo masculino e 5.321 do 
sexo feminino. Ressalta-se que a população na faixa etária de 20 a > de 60 anos consiste num total de 3.111 homens e 3.498 mulheres.

Os momentos da intervenção ocorreram no grupo Conversa Entre Mulheres, do CSF, que consiste num espaço de convivência, cuidado e promoção da saúde, no qual são realizados planejamentos de forma mensal e definida juntamente com as participantes a temática de cada encontro, com o intuito de torná-lo mais interativo, dando espaço e autonomia às mulheres. As reuniões do grupo acontecem semanalmente às terças-feiras no turno da tarde, passou por alguns ajustes e atualmente acontece quinzenalmente às quartas-feiras à tarde. Nesse sentido, os momentos da intervenção ocorreram de forma quinzenal e foram desenvolvidos entre o período de novembro/2019 e janeiro/2020.

A reunião do grupo de mulheres ocorreu por um determinado tempo no CSF Padre Palhano (como é popularmente conhecido pela comunidade), porém, num dado momento observou-se a necessidade de nos aproximarmos mais das usuárias e levar o grupo para dentro da comunidade.

Dessa forma, os encontros ocorreram na própria comunidade, num espaço cedido por uma moradora do bairro, que é uma líder comunitária e religiosa, que desenvolve algumas atividades nesse local, como missas, terços, cursos, entre outros. O espaço, chamado de Centro Catequético Santa Luzia, consiste num ambiente agradável, acolhedor, próximo à residência das participantes, sendo um espaço propício e adequado para a realização das atividades. Apresentou-se, portanto, como equipamento social potente dentro do território, que permitiu a socialização, a integração, estabelecimento de vínculos, no qual as usuárias sentem-se seguras, não havendo presença de estigmas, preconceito ou qualquer forma de desrespeito que viessem a afetá-las negativamente, principalmente por ser um espaço mais reservado, resguardando o sigilo.

Ressalta-se que a estratégia utilizada foi vista de forma positiva, fato esse que possibilitou maior vínculo com as usuárias, uma vez que fomos para além dos muros do CSF para desenvolver atividades de educação e promoção da saúde.

O Ministério da Saúde, em seu Caderno de Atenção Básica relata que os profissionais de saúde devem estar atentos à saúde da mulher, principalmente aquelas que estão em situação de violência, pois estas são usuárias assíduas desses serviços de saúde. Geralmente estas são vistas como "poliqueixosas", devido às suas queixas muito vagas e crônicas, as quais em exames de investigações realizados os resultados são normais. Antes de medicá-las, os profissionais devem procurar conhecer a história de vidas dessas mulheres, pois o tratamento meramente sintomático manterá oculto o problema. Torna-se relevante que esses sujeitos desenvolvam atitudes, estratégias e ações que possibilitem às usuárias sentirem-se acoIhidas e apoiadas. Ou seja, nessa perspectiva, esses profissionais terão mais vínculo com essas usuárias (BRASIL, 2017).

Sendo assim, o CSF, como dispositivo da Atenção Primária à Saúde (APS), na Estratégia de Saúde da Família (ESF), caracteriza-se como espaço favorável para o desenvolvimento de educação em saúde em grupos. Importa igualmente levar em consideração que é de extrema importância realizar ações de promoção à saúde, abrangendo concepções voltadas à mudança de comportamento dos indivíduos, focando nos estilos de vida, como também apoiando uma concepção ampla de saúde direcionada à qualidade de vida (SILVA et al., 2019).

Importante ressaltar que um dos aspectos significativos a ser considerado na formação de um grupo e sua do mesmo é a sua sustentabilidade. No decorrer da existência da ESF é bem comum o relato de profissionais sobre as inúmeras tentativas de começar um trabalho com grupos. Observa-se que inicialmente comparece certo número de pessoas, que acabam por ir se afastando e aos poucos o grupo vai se desfazendo, provocando certa frustração nos profissionais de saúde implicados e o descrédito por parte da população local (SILVA et al., 2019).

Os sujeitos do estudo foram mulheres, usuárias da atenção primária, que fazem parte do grupo "Conversa Entre Mulheres", do CSF Padre Palhano. Em agosto de 2019 o grupo contava com aproximadamente 12 mulheres integrando-o, e como participantes da intervenção contavam com 7 mulheres.

Além dos sujeitos anteriormente descritos, contamos como apoiadores da intervenção com profissionais da Equipe Mínima do CSF e da equipe multiprofissional, tanto do Núcleo Ampliado em Saúde da Família (Nasf-AB) quanto da Residência Multiprofissional em Saúde da Família (RMSF), que tiveram interesse na temática, com o propósito da ampliação de saberes, por meio da Educação Permanente e Educação em Saúde (o que foi realizado na intervenção), e no conhecimento do fluxo de atenção, cuidado e manejo de situações de violência contra a mulher.

Nesse sentido, o estudo considerou alguns critérios para a seleção do perfil das participantes. Os critérios de inclusão para a identificação das partici- 
pantes da intervenção foram os seguintes: mulheres maiores de 18 anos, moradoras do território do Padre Palhano; participantes do grupo Conversa Entre $\mathrm{Mu}$ Iheres, do CSF Padre Palhano; usuárias que vivenciam e/ou presenciam situação de violência, usuárias que desejam conhecer os serviços de atenção à mulher em situação de violência, profissionais da Equipe Mínima, Nasf-AB e Residentes em Saúde da Família, do CSF Padre Palhano, que tiverem interesse na temática.

Da mesma forma, foram definidos os critérios de exclusão, os quais inviabilizaram a participação no estudo, como: usuárias que não possuem capacidade civil plena, isto é, que não têm possibilidade plena de exercer pessoalmente os atos da vida civil; menores de 18 anos; que mantinham domicílio em outro território; que não apresentavam o desejo de participar do grupo de mulheres; profissionais que não atuam no sistema de saúde do município de Sobral; profissionais que não atuam no CSF do Padre Palhano.

A intervenção ocorreu de forma grupal, quando foram realizados os momentos de educação em saúde voltados para usuárias que vivenciam ou presenciam situação de violência contra a mulher.

Em casos em que alguma participante teve dificuldade de expor determinada situação de violência diante do grupo, foram oportunizados a escuta e o acolhimento por meio de atendimento individual com os profissionais do CSF ou da rede de cuidado a situações de violência de Sobral.

Do mesmo modo, quando alguma das participantes relatou sofrer algum tipo de violência, durante sua participação na pesquisa, algumas condutas foram adotadas, tais como: acolhimento e escuta qualificada juntamente com a psicóloga do Nasf-AB e enfermeira da Unidade, bem como encaminhamento ao Centro de Referência da Mulher.

O Centro de Referência da Mulher consiste em um serviço de atendimento que está inserido em uma rede de enfrentamento à violência contras as mulheres, e dispõe de equipe multiprofissional especializada (constituída por assistente social, psicólogo, pedagoga, advogado, gerente e coordenação), od quais acoIhem a vítima e realizam orientações e encaminhamentos jurídicos, a fim de promover a superação da situação.

Na execução da intervenção realizamos três momentos temáticos por meio de oficinas, nas quais foram abordados assuntos pertinentes à violência contra a mulher.
Tais momentos configuraram-se como espaços de educação em saúde, realizados por meio de rodas de conversas. O método da roda de conversa, em que as participantes ficaram sentadas e em círculo, consiste num recurso para a educação em saúde, de acordo com Freire (2003), pois possibilita um encontro dialógico, criando a possibilidade de produção e troca de saberes sobre as vivências das participantes. Ou seja, na roda, a fala é compreendida como expressões de modos de vida. A educação em saúde, nesse sentido, teve como proposta formar o pensamento crítico das participantes para reconhecerem seus problemas e atuarem individualmente ou coletivamente para solucioná-los (BRASIL, 2001).

Com o intuito de alcançar os objetivos, no entanto, os momentos foram delineados da seguinte forma:

- Primeiro momento: Foi realizado por meio da roda de conversa, quando tivemos um momento inicial de apresentação, socialização dos participantes, bem como lhes serão explicados os objetivos e demais momentos dos encontros do Projeto. Posteriormente foram espalhadas tarjetas no chão com os tipos de violências sofridas pelas mulheres, a fim de facilitar e direcionar odiálogo.

- Segundo momento: Foi apresentada às participantes a história do empoderamento feminino, por meio de recursos como slides, vídeos ou figuras, a fim de propiciar uma reflexão crítica sobre o papel da mulher na sociedade e sobre a importância dos movimentos feministas na atualidade. Foram possibilitados momentos de fala a fim de potencializar uma educação dialógica e significativa.

- Terceiro momento: Foram apresentados nesse último momento da intervenção, os equipamentos e fluxos de proteção. Foram explicitados os dispositivos de atendimento a mulheres em situação de violência, bem como fluxos de atendimentos e rede de suporte. Também foi possibilitado espaço para dúvidas, questionamentos e reflexões.

- Com a realização da intervenção pretendeu-se alcançar os seguintes resultados:

- Fortalecimento do grupo Conversa Entre Mulheres no CSF Padre Palhano, no que respeita à participação, à autonomia e ao empoderamento feminino. 
- O pensamento crítico das participantes no reconhecimento e resolução dos seus problemas.

- Uma maior vinculação entre as usuárias vítimas de violência e destas com o CSF Padre Palhano.

- Possibilitar a identificação das usuárias sobre difusão de conhecimentos e informações sobre as redes de apoio a mulheres em situação de violência.

Ao final de cada encontro foi promovido um momento de avaliação, que será descrito a seguir.

No presente projeto foi utilizado o diário de campo, que consiste num instrumento de anotações, comentários e reflexão, para o uso individual do pesquisador. Este instrumento, por sua vez, facilita o hábito de escrever e observar com atenção, descrever com precisão e refletir sobre os acontecimentos. Foi utilizado para fins descritivos, buscando captar uma imagem da realidade, com seu máximo de detalhamento, incluindo aspectos do local, pessoas, ações e conversas observadas. O diário de campo não é uma técnica isolada de coleta de dados em pesquisa qualitativa, não necessita de conhecimento aprofundado para o seu uso e busca a checagem das informações e explorar tópicos de difícil abordagem (FREITAS; PEREIRA, 2018).

Ressalta-se que não há um instrumento mais acertado, este vai depender do tipo de pesquisa e de dados que se pretende. Levando em consideração a possibilidade de algumas integrantes do grupo possuírem baixa escolaridade, a avaliação do projeto de intervenção deu-se de forma verbal, realizada ao final de cada encontro, seja ela individual, coletiva ou com a participação de profissionais. Utilizamos, portanto, imagens que expressam os diferentes níveis de satisfação em relação à atividade que foi desenvolvida. Tais níveis de satisfação das usuárias com o momento serão denominados como "Muito satisfeito", "Satisfeito", "Pouco satisfeito" e "Insatisfeito". De acordo com a escolha da imagem que representou o grau de contentamento desta, cada participante foi convidada a expressar verbalmente o porquê desta escolha, em qual aspecto o momento poderia ter sido mais proveitoso ou a contribuição da atividade para seu desenvolvimento.

Outro fator levado em consideração como ponto avaliativo foi o percentual da assiduidade das participantes, que foi realizado a partir de registros de frequência. No que tange aos aspectos éticos, o projeto de pesquisa está alinhado aos preceitos da Resolução
466 de dezembro de 2012, do Conselho Nacional de Saúde (CNS), que garante os referenciais da bioética, orientando como proceder e quais os cuidados necessários ao se realizar pesquisa com seres humanos.

A resolução supracitada incorpora, sob a ótica do indivíduo e das coletividades, os princípios da bioética, tais como: autonomia, beneficência, não maleficência, justiça e equidade (BRASIL, 2013).

$\mathrm{O}$ presente projeto trabalha os sujeitos e a educação em saúde, tratando de assuntos que podem afetar direta ou indiretamente a saúde destes, levando em consideração que a mesma não pode ser vista apenas como processo saúde-doença, mas que devemos compreender o indivíduo em sua totalidade. Neste sentido, empoderar as participantes, falando de assuntos como a violência contra as mulheres e apresentando as redes e equipamentos que trabalham nessa perspectiva, é dar-lhes autonomia para identificar e/ou reconhecer a situação em que vivem, bem como lidar com esses problemas e a sua realidade.

O projeto pesquisa-intervenção foi submetido à Comissão Científica de Sobral, pelo Sistema Integrado da Comissão Científica (SICC). Posteriormente, após a emissão do parecer favorável, o projeto foi submetido ao Comitê de Ética em Pesquisa com Seres Humanos (CEP) da Universidade Estadual Vale do Acaraú (UVA), sob parecer $n^{\circ} 3.685 .749$ aprovado com Certificado de Apresentação para Apreciação Ética (CAAE) sob o $n^{\circ}$ 17834619.0.0000.5053. Somente após a devida aprovação teve início a execução do projeto.

Vale ressaltar que antes de iniciar a execução do estudo foi apresentado o Termo de Consentimento Livre e Esclarecido - TCLE - que trata da autorização da participação das usuárias no projeto e sobre o uso de dados para fins científicos (que são resguardados de acordo com a ética), o qual foi lido e assinado pelasparticipantes.

Ressalta-se, ainda, que a qualquer momento, sem necessidade de justificativa ou prejuízo de qualquer ordem, seja moral, jurídica ou financeira, as participantes poderiam desistir de sua colaboração.

É importante destacar, igualmente, que a intervenção optou por procedimentos que assegurassem a inclusão, respeito, autonomia, a confidencialidade, bem como zelo pela privacidade das participantes.

\section{RESULTADOS E DISCUSSÃO}

A execução da intervenção deu-se em três encontros temáticos por meio de oficinas, nos quais foram abordados assuntos correlatos à violência contra a mulher, quando foi possível a realização de educa- 
ção em saúde e rodas de conversa, uma vez que o método da roda possibilita um encontro dialógico e a troca de saberes a partir das vivências das participantes.

A princípio foi importante a colaboração dos Agentes Comunitários de Saúde (ACSs), que realizaram a divulgação e entrega dos convites para os encontros, contribuindo no vínculo entre CSF e usuárias.

Para os encontros, contamos com 7 participantes e com o apoio de 3 profissionais de saúde, a saber: uma Assistente Social, uma profissional de Educação Física da Residência Multiprofissional em Saúde da Família e uma Agente Comunitário de Saúde (ACS).

\section{Primeiro momento: Dialogando sobre as expressões da violência contra a mulher}

Foi realizada uma dinâmica de apresentação, quando foi entregue uma rosa para uma das participantes e solicitado que esta falasse seu nome e relatasse um pouco das suas expectativas sobre os momentos da intervenção. Logo após esta repassava a rosa para outra participante dar continuidade à dinâmica. Esse momento de socialização foi de suma importância para que as participantes se sentissem mais à vontade na hora de se expressar em público.

Posteriormente, com o emprego do método da roda de conversa, em que as participantes ficaram sentadas e em círculo, foi dado início à temática proposta para o primeiro encontro. Para esse momento foram utilizadas palavras geradoras do método de Paulo Freire, a fim de fomentar e direcionar a roda de conversa; foram espalhadas tarjetas no chão com os tipos de violências sofridas pelas mulheres, como: violência física, psicológica, sexual, patrimonial, moral, doméstica, intrafamiliar, de gênero, institucional e simbólica.

Ao colocar cada tarjeta no chão, perguntou-se para as participantes se estas conheciam esse tipo de violência e de que forma se apresentava. Observou-se que elas mostravam algumas reações perante alguns dos tipos de violência, demonstrando não conhecer e não saber como se manifesta, ou ainda que não sabiam que essas características se configuravam como uma forma de violência contra a mulher. Posteriormente foi abordado detalhadamente sobre cada uma delas, a fim de que pudessem compreender e identificar as diversas formas de violência, tornando-as multiplicadoras das informações e buscando efetivar seus direitos e proteção.
No desenvolvimento da atividade percebemos que as participantes inicialmente estavam um pouco envergonhadas, mas que no decorrer da roda de conversa essa situação foi superada e elas foram participando e se expressando diante do grupo.

A fim de zelar pela privacidade e garantir o sigilo profissional, foram utilizados pseudônimos para as participantes. Cada uma recebeu o nome de uma flor e, no decorrer da descrição e discussão da pesquisa, elas foram chamadas por: Margarida, Lírio, Rosa, Girassol, Orquídea, Tulipa e Violeta.

Ao final do encontro tivemos um momento para avaliação, quando foram distribuídas plaquinhas com imagens que expressam os diferentes níveis de satisfação em relação à atividade desenvolvida. As participantes avaliaram como muito satisfatório e relataram que as informações abordadas eram de grande importância para entender como de fato a violência atinge as mulheres e o quanto ela está presente no cotidiano e que, muitas vezes, passa despercebida por estas, pelo simples fato de associarem violência somente às agressões físicas, quando em suas falas relatam:

É importante trazer esses assuntos pra gente, porque a gente fica mais informada e entende que a violência não é só quando a mulher apanha (Margarida).

Fico triste em saber que nos dias de hoje a muIher ainda passa por essas coisas, isso tem que acabar (Girassol).

Eu gostei de saber dessas informações e vendo assim, eu acho que até passo por alguma dessas (Margarida).

Refletindo a partir das falas proferidas a partir da intervenção, o que pode ser constatado é o que nos trazem Leite et al. (2015), pois estes afirmam que a maioria das mulheres conhece alguns fatores de risco para a violência, porém aparentam não saber agir no sentido de evitá-las, além de encará-las como "algo comum" no cotidiano do casal. Dessa maneira, trazer à tona essa intervenção e temática favorece uma meIhor compreensão do seu contexto situacional para este fim e, com isso, as mulheres passam a entender melhor seu cotidiano.

Vale ressaltar que todas essas formas de violência se configuram crime, e toda e qualquer muIher que se sentir afetada por qualquer uma dessas deve procurar as leis que Ihe asseguram a devida proteção. 
Segundo momento: Dialogando sobre a história e importância do empoderamento feminino no contexto da violência contra a mulher

No segundo momento da intervenção foi apresentada às participantes a história do empoderamento feminino, por intermédio de recursos como vídeos, os quais propiciaram uma reflexão crítica sobre o papel da mulher na sociedade e sobre a importância dos movimentos feministas na atualidade, na luta pela garantia e efetivação dos direitos da mulher.

Para esse momento foram preparadas duas ações, que contribuíram para o objetivo do encontro alcançado. Como de costume, inicialmente foi realizada uma dinâmica de acolhida, no intuito de deixar o encontro mais leve e acolhedor.

A primeira ação consistiu na exibição de um filme chamado "Preciosa - Uma História de Esperança", que retrata a história de uma adolescente de 16 anos que sofreu uma série de privações na juventude, que era violentada pelo pai (inclusive sexualmente, o que gerou dois filhos que foram frutos dessa violência) e que também era abusada pela mãe, mas que por meio da ajuda e apoio de uma professora conseguiu sair dessa situação de violência e buscar justiça para a situação vivida. Um filme bem delicado, que aborda diversos temas, tais como: preconceito, violência doméstica, estupro, conflitos familiares, gravidez na adolescência, mas que retratam a realidade de muitas mulheres.

A segunda ação, por sua vez, consistiu na exibição de um vídeo com depoimentos reais de mulheres que sofreram algum tipo de violência pelos parceiros, no qual relatam em quanto tempo e como conseguiram identificar que estavam vivendo uma situação de violência e como conseguiram sair desse ciclo. Nos depoimentos as mulheres abordam ainda como os movimentos feministas contribuíram para a compreensão sobre o papel da mulher na sociedade, de que forma essa percepção e esse empoderamento feminino contribuíram como fator potencializador, encorajador e libertador diante dessas situações de violência.

Posteriormente foi proporcionado um momento de fala, o que potencializou uma educação dialógica e significativa, ocasião em que as participantes puderam discorrer sobre suas impressões e percepções diante do filme e vídeo assistidos.

A gente vê isso e pensa que é só em filme, isso existe na vida real, pai estuprando filha, só o que tem! (Rosa).
Queria saber como a gente faz pra ajudar em casos assim? Porque a gente vê e não sabe o que fazer pra ajudar (Rosa).

E não é só pai não, às vezes é tio que faz essas coisas com a mulher. Por isso as mulheres devem tomar cuidado quando tem filha em casa, e é mãe solteira, não porque não deve namorar, pois ela tem mais é que ser feliz, mas é que às vezes a gente não conhece quem coloca dentro da nossa casa e às vezes o namorado ou padrasto pode faz isso com nossas filhas (Tulipa).

Ainda bem que tem mulher que consegue sair, né. Porque às vezes tem mulher que morre vivendo assim porque não consegue sair disso (Orquídea).

Infere-se, portanto, que o segundo momento da intervenção resultou numa estratégia positiva, pois gerou comoção e reflexão acerca da temática, uma vez que as participantes se sensibilizaram e se inquietaram diante da situação sofrida por várias mulheres, seja por alguém da família que vivencia situação de violência, ou com amigas, vizinhas, conhecidas. Dessa maneira, na atividade realizada, algumas das participantes limitaram-se a falar, pois estavam um pouco emocionadas com os relatos apresentados durante o momento.

Outra situação que chamou bastante a atenção desde o início desse segundo encontro foi o fato de uma das participantes da intervenção estar machucada na região do rosto, com os olhos um pouco roxos e inchados e alguns ferimentos na região dos lábios. Ao ser questionada por uma das participantes o motivo dos ferimentos, ela relatou que havia caído.

No intuito de não constranger e nem expor a participante perante o grupo, ao final da intervenção foi reservado um momento para atendimento individual com ela. Ao realizar a escuta constatou-se que o caso se tratava de violência. Diante dessa situação, foi conversado e repassadas orientações a essa participante sobre os cuidados e encaminhamentos necessários, entre eles: cuidados com os ferimentos no CSF; agendamento de atendimento/acompanhamento psicológico levando em consideração que os problemas enfrentados estão afetando sua saúde mental e orientação quanto aos procedimentos e fluxos de proteção à mulher em situação de violência.

Ressalta-se que foi realizada a notificação de violência do caso, por meio do preenchimento da Ficha de Notificação Individual (FNI), de registro de violência interpessoal/autoprovocada, do Sistema de Informação de Agravos de Notificação (Sinan) e encaminhado para a Vigilância Epidemiológica. 
Como neste caso supracitado, ressalta-se que a equipe de saúde pode apoiar essas mulheres no reconhecimento da violência, propiciando espaços de escuta individual e coletivas nas unidades de saúde, com o propósito de identificar as situações de risco, bem como traçar as devidas medidas e ações preventivas. Dessa forma, ao se deparar com essas situações de risco, os profissionais de saúde devem estimular a muIher a procurar atendimento ou grupos de reflexão. Além disso, corroborando essa questão, adverte-se que essa rede de apoio deve atuar no intuito de assistir essas mulheres para que não passem por situações semelhantes a essa (BRASIL, 2017).

Infelizmnte, até o final da intervenção essa participante, apesar de compreender a sua situação, ainda estava inserida no contexto de violência, em decorrência de alguns fatores econômicos e sociais.

Terceiro momento: Identificando os equipamentos sociais e fluxos de proteção voltados a mulheres em situação de violência

E por fim, no terceiro e último momento da intervenção foram apresentados os equipamentos e fluxos de proteção, quando foram explicados sobre os dispositivos de atendimento a mulheres em situação de violência, bem como fluxos de atendimentos e rede de suporte.

Para a realização desse momento, no objetivo de nortear a roda de conversa, foram utilizadas palavras geradoras e espalhadas algumas tarjetas no chão com os serviços que prestam atendimento às mulheres vítimas de violência, tais como: Centro de Referência, Casas-Abrigo, Delegacias Especializadas de Atendimento à Mulher, Defensoria da Mulher, Juizados de Violência Doméstica e Familiar Contra a Mulher, Central de Atendimento à Mulher (Ligue 180), Ouvidorias, Cras e Creas, Polícia Civil e Militar, Instituto Médico Legal (IML), Serviços de Saúde voltados para o atendimento dos casos de violência sexual.

Um fator que foi bem significativo e que chamou a atenção delas foi o número de instituições que atuam na resolução da problemática. Antes de abordar sobre esses instrumentos, foi perguntado quais os serviços que elas conheciam que atuam na resolução dessa demanda. A maioria respondeu Delegacia da Mulher e outras relataram não conhecer. Diante disso, foi explicitado serviço por serviço a fim de gerar meIhor compreensão por parte delas.
O momento foi muito rico e proveitoso, as participantes demonstraram interesse pela temática e foram bem participativas, uma vez que tiraram dúvidas, levantaram alguns questionamentos, bem como trouxeram algumas reflexões.

Ao final da ação foi disponibilizado um tempinho para a avaliação da ação, ocasião em que as participantes puderam expor suas impressões sobre o momento:

É bom a gente saber dessas informações, pois quando a gente ver alguém passando por isso ou até nós mesmas, a gente já sabe quem procurar pra pedir ajuda (Margarida).

Acho que toda mulher deve ficar informada disso... são informações valiosas e que só vêm a ajudar. Temos que fazer valer nossos direitos (Rosa).

E pensar que já passei por esse tipo de situação. Apanhando de marido bêbado, que chegava em casa procurando briga. Graças a Deus saí disso e hoje vivo bem (Girassol).

Eu gostei de participar desses encontros, a gente aprendeu muita coisa nova. E depois desse grupo, vi que passava por algumas coisas dessas e aprendi a cortar e conversar com o meu novo companheiro sobre isso (Margarida).

Dessa maneira, deve-se refletir que as redes de apoio e atenção, fomentadas pelas ações que elas oferecem, se constituem na articulação entre instituições governamentais, não governamentais e comunidade, e visam a ampliar e melhorar a qualidade do atendimento, ao encaminhamento necessário e o desenvolvimento e articulação de estratégias efetivas para prevenção de assuntos específicos, principalmente os casos de violência contra a mulher (LETTIERE; NAKANO, 2015).

Contribuindo com o exposto, Morais e Rodrigues (2016) afirmam que momentos como estes, assim como a promulgação da Lei Maria da Penha (BRASIL, 2010), foram significativos na luta e mobilização das mulheres brasileiras que perduraram por muitos anos, e a sua efetivação foi um passo muito importante para o enfrentamento da violência contra a mulher, que garante a proteção desta e de seus filhos para prevenir e impedir a continuação da situação de violência.

Dessa forma, conclui-se que o trabalho foi exitoso, levando em consideração que as participantes avaliaram como muito satisfatória a atividade desenvolvida e fizeram colocações bem pertinentes. Ao serem questionadas sobre como que elas reagiriam se vivenciassem ou viessem a se deparar com alguma mulher em situação de violência, frisaram que a par- 
tir dos conhecimentos adquiridos nos encontros, hoje elas saberiam como lidar e que sem dúvida denunciariam situações semelhantes.

\section{CONSIDERAÇÕES FINAIS}

A violência ainda é algo muito presente na vida das mulheres e, como vimos, ela pode se expressar de várias formas, trazendo consequências negativas com impactos na saúde, seja ela física ou emocional, havendo urgência em instituir programas para detecção precoce e para intervenções efetivas. Diante disso, torna-se cada vez mais necessário aumentar os espaços de discussões no intuito de fortalecer a luta das mulheres por garantias de direitos e disseminar informações.

Com a realização das ações da pesquisa-intervenção, foi possível observar que as atividades desenvolvidas foram exitosas e corresponderam aos objetivos propostos, uma vez que, com a realização do projeto de intervenção ocorreu o fortalecimento do grupo Conversa Entre Mulheres, gerou o pensamento crítico das participantes no reconhecimento e resolução dos seus problemas, tornando-as multiplicadoras do saber e levando informações para outras mulheres que vivenciam situações de violência, bem como a identificação das redes de apoio.

Outro fator positivo resultante das ações da pesquisa foi o fortalecimento do vínculo entre as usuárias e o Centro de Saúde da Família (CSF). Estreitar esses laços foi de suma importância, uma vez que as mulheres que estão em situação de violência procuram o CSF frequentemente, mas com outras queixas e, por meio desse vínculo essas mulheres se sentirão mais seguras e amparadas para relatar alguma situação de violência que estejam sofrendo. Neste sentido constatamos que o vínculo é um elemento fundamental na relação entre usuários e unidade de saúde.

Entre as dificuldades encontradas na realização da intervenção, houve uma que se mostrou mais expressiva, ou seja, a ausência dos profissionais da Equipe Mínima, além do ACS, para dar suporte e continuidade às atividades a serem desenvolvidas no grupo, que ocorre na comunidade, mas que é de referência do CSF.

Para que o grupo tivesse viabilidade foi essencial realizar os planejamentos, a disponibilização do espaço para a constituição do grupo dentro da comunidade. Ressalta-se a importância e relevância da contribuição dos residentes multiprofissionais em saúde da família e do ACS de referência da área em que o grupo de mulheres ocorre. Estes foram fundamentais para o desenvolvimento da intervenção.

A experiência viabilizou às pesquisadoras uma maior aproximação com os determinantes e condicio nantes sociais de saúde do território, tais como: moradias inadequadas, relações familiares adoecedoras, dentre outros. Ainda, um olhar cuidadoso voltado para as mulheres vítimas de violência, que é um fator que as afeta no processo saúde-doença.

\section{REFERÊNCIAS}

BAZANINI, Roberto; RIBEIRO, Hewdy Lobo; BAZANINI, Homero Leoni. Estratégia dos negócios: Obstáculos encontrados para a consolidação da TV Digital no Brasil e seus impactos na cadeia produtiva eletroeletrônica na perspectiva da teoria dos stakeholders. Revista de Negócios, ISSN 19804431, Blumenau, Brasil, v. 19, n. 1, p. 70-93, jan./mar. 2014. BRASIL. Ministério da Saúde. Fundação Nacional de Saúde. Oficinas de educação em saúde e comunicação. Educação em Saúde. Brasília: Ministério da Saúde, 2001. Disponível em: https://mosquito.saude.es.gov.br/Media/dengue/Arquivos/Oficinas_Educacao.pdf. Acesso em: 25 jul. 2020.

BRASIL. Procuradoria Especial da Mulher. Lei Maria da Penha Lei no 11.340. Câmara dos deputados. Brasília, 2010. 37 p.

BRASIL. Ministério da Saúde. Conselho Nacional de Saúde; Brasil. Resolução no 466, de 12 de dezembro de 2012. Diário Oficial da União, 2013.

BRASIL. Ministério da Saúde. Portaria no 2.436, de 21 de setembro de 2017. Política Nacional de Atenção Básica, estabelecendo a revisão de diretrizes para a organização da Atenção Básica, no âmbito do Sistema Único de Saúde (SUS). Brasília, DF: Ministério da Saúde, 2017. Disponível em: http://www.brasilsus.com.br/index.php/legislacoes/ gabinete -do- -ministro/16247-portaria-n-2-436-de-21-de-setembro-de-2017. Acesso em 28 out. 2020.

ENGEL, C. L. et al. A violência contra a mulher. Brasília: Ministério da Economia, 2015. Disponível em: https://www. ipea.gov.br/retrato/pdf/190215_tema_d_a_violenca_contra_mulher.pdf. Acesso em: 28 de out.2020.

FREIRE, P. Pedagogia da esperança: um reencontro com a pedagogia do oprimido. Rio de Janeiro: Paz e Terra, 2003.

FREITAS, M.; PEREIRA, E. R. O diário de campo e suas possibilidades. Quaderns de Psicologia, 2018, v. 20, n. 3, p. 235244, 2018. Disponível em: file:///C:/Users/stela/Downloads/1461-5225-2-PB.pdf. Acesso em: 28 out. 2020.

GUIMARÃES, M. C.; PEDROZA, R. L. S. Violência contra a mulher: problematizando definições teóricas, filosóficas e jurídicas. Psicologia \& Sociedade, Brasília, DF, Brasil, Universidade de Brasília, 27(2), p. 256-266, 2015. Disponível em: https://www.scielo.br/pdf/psoc/v27n2/1807-0310-psoc-27-02-00256.pdf. Acesso em: 29 out. 2020. 
LETTIERE, A.; NAKANO, A. M. S. Rede de atenção à mulher em situação de violência: os desafios da transversalidade do cuidado. Revista Eletrônica de Enfermagem,v. 17, n. 4, 2015.

LEITE, M. C. F. et al. Violência contra a mulher: caracterizando a vítima, a agressão e o autor. Revista de Pesquisa Cuidado é Fundamental On-line, v. 7, n. 1, 2015.

MORAIS, M. O.; RODRIGUES, T. F. Empoderamento feminino como rompimento do ciclo de violência doméstica. Revista de Ciências Humanas, Viçosa, v. 16, n. I, p. 89-103, 2016.

ROMAGNOLI, R. C. O conceito de implicação e a pesquisaintervenção institucionalista. Revista Psicologia \& Sociedade, v. 26, n. 1, 2014.

SILVA, A. C. S. da et al. A Atenção Primária sob a ótica dos usuários do Sistema Único de Saúde: uma revisão bibliográfica. Revista Sustinere, Rio de Janeiro, v. 7, n. 1, p. 46-72, jan./jun. 2019. Disponível em: file:///C:/Users/stela/Downloads/36184-148671-1-PB.pdf. Acesso em: 28 out. 2020.

SOBRAL. Secretaria de Saúde. Territorialização do CSF Herbert de Sousa. Sobral, 2017. (Mimeo). 